\title{
Lost by Definition: Why Boredom Matters for Psychology and Society
}

\author{
Erin C. Westgate ${ }^{1}$ \\ Brianna Steidle ${ }^{1}$ \\ ${ }^{1}$ University of Florida, Department of Psychology, \\ 945 Center Drive, Gainesville, FL 32603
}

***PREPRINT***

Final accepted version in press at Social and Personality Psychology Compass

\begin{abstract}
Author Note
The research reported here was supported by a Foundation for Personality and Social Psychology Heritage Dissertation Research Award and National Science Foundation Grant BCS 1423747. We are grateful to Shige Oishi and Stephanie Wormington for their insight on portions of the manuscript. Portions of this work appeared previously in the first author's dissertation and newsletter. Correspondence concerning this article should be addressed to Erin C. Westgate, Department of Psychology, Gainesville, FL 32603. E-mail: erinwestgate@ufl.edu.
\end{abstract}




\begin{abstract}
Long overlooked, boredom has drawn increasing attention across multiple subfields of psychology (including clinical, developmental, educational, cognitive, and industrial/organizational psychology), as well as economics, philosophy, neuroscience, and animal cognition. In this paper, we review and integrate this work by providing a social psychological perspective on boredom as an emotion, and its role in signaling the need for change to restore successful attention in meaningful activity. In doing so, we discuss the implications of that approach for understanding boredom cross-culturally and cross-species, and identify opportunities for targeted interventions to reduce boredom and improve well-being.
\end{abstract}

Keywords: boredom, meaning, attention, motivation, emotion 
What do air traffic controllers, security guards, and anesthesiologists share in common? During a quiet overnight shift in 2011, the Cleveland airspace was jarred by audio from Samuel L. Jackson's Cleaner; the inadvertent transmission exposed the air traffic controller responsible, caught watching a crime thriller instead of the sky (Lowy \& Henry, 2011). Just last year, a security guard had to call police to release him from handcuffs — after he handcuffed himself out of boredom and lost the key (Darrah, 2019). And as a borrowed medical adage tells us, the profession of anesthesiology is "99\% boredom and 1\% panic" (Novak, 2012). Though professionals in these careers work critical jobs requiring long periods of vigilance, technological advances have made their day-to-day responsibilities safer and easier. But as an unintended side effect, these same lifesaving technological improvements may be making workers profoundly bored (Cummings et al., 2015).

None of us like to be bored. In one study (Wilson et al., 2014), $67 \%$ of men and $25 \%$ of women chose to give themselves an electric shock rather than be bored while sitting alone with their thoughts. Indeed, boredom has been linked to a wide variety of "bad" behavior, from selfharm and substance use (Havermans et al., 2015; Nederkoorn et al., 2016; Baldwin \& Westgate, 2020; Weybright et al., 2015; Westgate \& Fairbairn, 2020), to watching movies on the job instead of monitoring the skies. Any first-year college student on their way to a dreaded 8am class could articulate what we all intuitively know: surely we are better off without boredom.

But as happens so often in psychology, science does not support "common sense." Although boredom is unpleasant, it's an important signal; like all emotions, boredom conveys critical information about both our surrounding environments and internal psychological states (Clore et al., 2001). This information empowers us to resolve impending problems, and acts as a motivational force, steering our actions towards those that elicit positive feelings and curbing 
those that elicit negative ones (Baumeiseter et al., 2007). Boredom, in short, is a powerful indicator of whether our attention is successfully and meaningfully engaged, redirecting us when it is not (e.g., MAC model of boredom, Westgate \& Wilson, 2018).

\section{Lost by Definition: Is Boredom an Emotion?}

While thousands of studies have examined other emotions, such as sadness and anger, relatively few have examined the causes and consequences of state boredom. Why has boredom been so understudied in the literature at large, and in the psychology of emotion in particular? One straightforward possibility is that boredom, historically, has not always been defined as an emotion.

\section{Defining away: The disappearance of boredom}

Definitions can be boring, but they have consequences. And many definitions of emotion put forward in the 1970s and 80s specifically excluded boredom and similar emotions such as interest (Silvia, 2005, 2006, 2008), classifying them as cognitive states or "not-quite" emotions (Ekman, 1992; Lazarus, 1991; Johnson-Laird \& Oatley, 1992; Ortony, Clore, \& Collins, 1988; Ortony \& Turner, 1990). While there has been a great deal of debate about what constitutes an emotion (see Barrett et al., 2019, for an overview), most approaches agreed that boredom failed the central test: it wasn't affective. If emotions are "situated affective states" (Clore \& Ortony, 2013) - in other words, feelings about the goodness or badness of a specific thing - then boredom, as a presumably "neutral” state, didn't qualify. Instead, it was characterized variously as a non-affective cognitive state (Ortony et al., 1987), mood state (i.e., long-lasting and not tied to any particular object), or conceptualized as the absence of emotion altogether (Gasper, 2018). However, a considerable body of empirical evidence, not available at the time, suggests this view was premature. 
Rather than a neutral non-affective state, empirical data show that boredom is highly negative. In classic work, Ortony, Clore, \& Foss (1987) used linguistic conventions to determine which states constitute emotions (e.g., anger) and which don't (e.g., hunger). They used people's natural linguistic categories to classify which terms map onto (a) internal mental (b) affective (c) states, the three prerequisites of an emotion. Critically, affective terms should seem equally emotional when expressed as states of being ("being angry) as when expressed as states of feeling ("feeling angry"; Clore, Ortony, \& Foss, 1987). And like other affective-cognitive emotions, people report that "being bored" is just as emotional as "feeling bored."1 This clever linguistic argument is mirrored in self-report data: participants asked to rate the valence of boredom overwhelmingly report that boredom is predominantly negative (van Tilburg \& Igou, 2016; Goetz et al., 2006, 2014). And, behaviorally, when given the choice many people choose negative stimuli (e.g., electric shocks, visually disturbing images; Bench \& Lench, 2019; Haverman et al., 2015; Nederkoorn et al., 2016; Wilson et al., 2014;) over feeling bored, suggesting that boredom is itself aversive. In other words, linguistic, self-report, and behavioral data converge to suggest that boredom is affective, and unpleasantly so.

However, this historical definition had consequences for who studied boredom and how. All research must balance the fundamental trade-off that internal validity often comes at the expense of external validity, and vice versa (Aronson et al., 1998; Finkel et al., 2015; Wilson et al., 2010). Disciplines vary in where they fall on this continuum, with some such as social psychology historically prioritizing experimentation and causal mechanism, and others prioritizing descriptive observation and real-world context. Thus, the same construct dispersed across different disciplines will come to be studied and conceptualized in different ways, not

\footnotetext{
${ }^{1}$ Interestingly, this same work a priori predicted that boredom would be a strictly cognitive and non-affective state; as such it has sometimes been used in support of the claim that boredom is not an emotion
} 
unlike how a species, dispersed across isolated geographies, will diverge in adapting over time to its new ecological niche (Darwin, 1859). As a "non-emotion," boredom was rarely the focus of experimental theoretical work on emotions in social psychology and affective science from the 1980s through the early 2010s (for a detailed overview, please see Westgate \& Wilson, 2018). However, boredom was studied extensively in domains of practical significance: in education (e.g., Pekrun, 2006; Troutwine \& O’Neal, 1981; Goetz et al., 2014) and the workplace (e.g., Fisher, 1993, 1998; Kass et al., 2001). Due to the critical importance of understanding how such outcomes unfold in real-world settings, boredom research in these areas generally gravitated towards methods that maximize these qualities, focusing largely on correlational designs, with an emphasis on individual differences. To a focus, in other words, on trait, rather than state boredom. At the same time, work on state boredom was ongoing in clinical psychology (Eastwood et al., 2012) and cognitive neuroscience (Danckert \& Merrifield, 2016). This work often didn't consider boredom to be an emotion, but rather a cognitive state or "feeling about thinking," and focused, accordingly, on the cognitive mechanism of attention (Danckert \& Eastwood, 2020). Both these I/O and educational approaches, and the cognitivelyfocused work on attention, made valuable and much-needed contributions to the study of boredom. However, they intersected only infrequently with theoretical work in emotion, and its emphasis on experimental methods and causality.

Growing mainstream interest in boredom brought a new wave of experimental studies to psychology in the early 2000s, and a renewed interest in the application of psychological theories of emotion to the study of boredom. New theoretical work argued that boredom's purpose was motivational, intended to regulate pursuit of goals (e.g., Bench \& Lench, 2013), meaning (e.g., Barbalet, 1999), and well-being (e.g., Elpidorou, 2014, 2020). Meanwhile, new empirical work 
found that boredom was often related to a lack of not only attention, but meaning (e.g., van Tilburg \& Igou, 2012, 2017; Schmeitzky \& Freund, 2012). However, these approaches largely investigated boredom's cognitive (e.g., attention) and motivational (e.g., meaning) components in isolation, and did not experimentally manipulate competing mechanisms (for an in-depth comparative review, please see Westgate \& Wilson, 2018). The Meaning and Attentional Components (MAC) model integrated these existing models, which tended to focus on single causal mechanisms (e.g., attention, meaning, goals), by bringing them together to specify when and how meaning and attention combine to produce feelings of boredom (Westgate \& Wilson, 2018). In doing so, it defined boredom not in terms of its experiential components (e.g., altered time perception) or downstream consequences (e.g., risk-seeking), but in terms of its key causal concept: "unsuccessful attentional engagement in valued goal-congruent activity" (p. 6). In other words, the MAC model treated boredom as an emotion, governed by the same constructivist theories that differentiate sadness, anger, and other specific emotions.

\section{Constructing boredom: Redefining boredom as an emotion}

If boredom is reclassified as an emotion, we can apply theories of emotion to its study. But what theories should we apply? Older theories (e.g., "basic emotions" theory) posit the existence of a small core set of biologically-based universal emotions, reliably identifiable by their facial, physiological, behavioral, and neural signatures. However, such theories are not consistent with a growing body of evidence that emotions cannot be distinguished by their

physiological signatures (Siegel et al., 2018), facial expressions (Gendron et al., 2014a, b; Barrett et al., 2019), or neural activity (Lindquist et al., 2012). Indeed, variation within emotions (e.g., expressions of anger) is often as great as variation between emotions (e.g., expressions of anger vs sadness; Barrett, 2009). Nor do emotions appear to be universal; work by Gendron et al. 
$(2014 a, b)$ find that different cultures categorize the same emotional expressions in very different ways.

If emotions are not universal, and cannot be distinguished by their experiential components (e.g., neural signatures, facial expression), what are emotions and how do we define them? Social psychology has long recognized that the key shared component that distinguishes specific emotions are peoples' subjective construals of the situation (e.g., two-factor theory of emotion, Schachter \& Singer, 1962). A racing heart can be interpreted as joy or anger, depending on the context. For instance, when we believe a blame-worthy person has violated an important boundary (Ortony et al., 1988), we experience anger - regardless of whether we yell, stomp out the door, or seethe quietly. From this perspective, "situated affective appraisals" do not cause emotion - rather, they are emotion (Clore \& Ortony, 2013).

Empirical evidence suggests this is true for boredom as well: that boredom, like other emotions, is reliably elicited by specific situational appraisals, namely lack of successful attentional engagement in valued goal-congruent (i.e., meaningful) activity (Westgate \& Wilson, 2018). Experimental manipulations find that people experience boredom when an activity is too easy or too hard to pay attention (Berlyne, 1960; Csikszentmihalyi, 2000; Danckert \& Merrifield, 2016; Eastwood et al., 2012; Fisher, 1993, 1998; Hamilton, 1981; Leary et al., 1986; Smith \& Ellsworth, 1985; Westgate \& Wilson, 2018; Westgate et al., 2017), or when it lacks meaning altogether (Locke \& Latham, 1990; Schmeitzky \& Freund, 2013; Westgate \& Wilson, 2018). Moreover, attention and meaning deficits independently elicit boredom; each is a sufficient (although not necessary) causal component (Westgate \& Wilson, 2018).

Appraisal theories of emotion have long recognized these appraisals as the key defining feature distinguishing specific emotions; modern constructivist theories take this insight further, 
to posit that emotions are not "natural kinds" at all (Barrett, 2006; Coan, 2010; Cunningham et al., 2007, 2013; . That is, just as the concept of "fruit" is contextually, rather than biologically, determined (e.g., a tomato is a vegetable in a salad, but a fruit in a botany lab), so too are emotions (Barrett, 2017). Like other constructed categories (e.g., sandwiches, birds), where and how to draw definitional boundaries between emotions rests on our concepts, rather than any inherent "natural" feature. Just as we picture robins to be prototypical birds and BLTs to be prototypical sandwiches, emotion categories (e.g., anger) too have prototypes. But these prototypes do not preclude the existence of non-prototypical category members, such as flamingoes, hot dogs, or - in the case of emotion - quiet anger, subdued joy, or restless boredom. For instance, whether boredom is primarily low or high arousal has been hotly contested, with some theories defining boredom as an inherently low arousal state (Posner et al., 2005; van Tilburg \& Igou, 2016). From a constructivist approach, the question is moot: arousal should vary. And indeed, this is consistent with the empirical evidence: boredom is just as frequently associated with high arousal as it is with low (e.g., Chin et al., 2017; Eastwood et al., 2012, Goetz et al., 2006, 2014, see Westgate \& Wilson, 2018 for overview).

In short, boredom “behaves” like an emotion (Clore \& Ortony, 2013; Barrett, 2017). In biology, species are classified not on the basis of their superficial similarity (e.g., phenotype) but on the basis of their evolutionary origins and development (Müller, 2007). Different species do different things, developmentally and ecologically. Do emotions and boredom do different things? Or do they share the same causal origins and mechanisms? The evidence above suggests they do. If boredom behaves, in all respects, like an emotion, the most parsimonious approach is to conclude it is one. 


\section{Emotions are States: The Trouble with Trait Boredom}

This approach likewise clarifies what we can and cannot learn about state boredom from past research on trait boredom. For historical reasons, the majority of past work has focused overwhelmingly on trait boredom, or "boredom proneness," by correlating differences in trait boredom with individual differences in outcome measures of interest (e.g., depression, anxiety). However, there are theoretical and methodological barriers to drawing inferences about emotional states from the study of traits. If trait boredom is thought to reflect how often or how intensely people experience state boredom, then measures of trait boredom ought to predict measures of state boredom during actual boring experiences. However, the two most common scales - the Boredom Susceptibility Scale (10-item subscale of the sensation seeking scale; Zuckerman et al., 1978) and the Boredom Proneness Scale (Farmer \& Sundberg, 1986) - suffer from conceptual ${ }^{2}$ and psychometric issues ${ }^{3}$; they correlate only weakly with each other $(r=.25$; Farmer \& Sundberg, 1986), and even more weakly with measures of lab-induced state boredom (Boredom Proneness Scale internal meta-analysis $r=.17$, revised Short Boredom Proneness Scale internal meta-analysis ${ }^{4} \mathrm{r}=.02$, Westgate, 2018).

This is consistent with experience sampling data, which suggests that "trait" boredom may largely reflect situational variance in activity (Chin et al., 2017), rather than trait-like

\footnotetext{
2 The creators of the Boredom Proneness Scale theorized that "boredom and depression can both be described as 'depressions' in mood," differing largely in intensity (Farmer \& Sundberg, 1986). Accordingly, many of the items on the Boredom Proneness Scale have significant overlap with clinical measures of depression and anxiety, and the BPS correlates quite well with clinical measures of depression $(r=.44-.54)$, hopelessness $(r=.41)$, loneliness $(r=$ $.53)$, and low subjective well-being $(r=-.42)$. Indeed, it correlates more strongly with such clinical measures than it does with lab-induced state boredom $(r=.17)$.

3 The Boredom Susceptibility Scale loads appropriately only for male participants, and not for female participants (Zuckerman et al., 1978). Likewise, the Boredom Proneness Scale has an unstable factor structure, with anywhere from two to seven factors, said to indicate boredom due to internal versus external stimulation. However, these factors appear to be artifacts of reverse-scored items and similarly worded items; when those items are rewritten, the Boredom Proneness Scale forms only a single factor (Struk et al., 2017).

${ }^{4}$ The Short Boredom Proneness Scale (SBPS) is a short revised form of the Boredom Proneness Scale that addresses its unstable factor structure, but not the theoretical framing of boredom as a less intense state of depression (Struk et al., 2017).
} 
individual differences. Indeed, recent longitudinal work found only $28 \%$ of variance in the BPS scale to be due to trait-like differences in boredom; the majority of variance (64\%) was due to measurement error (Gana et al., 2019).

\section{Boredom-as-Information}

Affect confers information about the goodness (or in boredom's case, primarily the badness) of its object. We infer that what feels good is good (Clore et al., 2001; Clore \& Tamir, 2002). Likewise, emotions provide information about the situations that elicited them. Anger alerts us to the possibility that someone has done something blame-worthy; sadness alerts us that a loss has occurred. Boredom acts, in short, as a dashboard light, alerting us to deficits in meaning or attention, and preventing us from persisting at activities that have little value (Chater, et al., 2019; Elpidorou, 2018; Westgate, 2020; Westgate \& Wilson, 2018). It does this in two ways: first, by motivating us to engage in actions and thoughts which we believe will be interesting and enjoyable, and to avoid those we believe (correctly or incorrectly) to be boring (Yamamoto \& Ishikawa, 2010). And, secondarily, by acting as a built-in reinforcement system, rewarding ways of thinking and behaving that are meaningful and optimally challenging (with pleasant feelings of interest and enjoyment, instead of boredom), and discouraging those that are not (see Figure 1).

We can therefore reduce boredom by resolving the underlying deficits in meaning and attention that produce it: 1) by regulating cognitive demands and resources (to restore attention), 2) by regulating goal value (to restore meaning), or 3) by switching activities altogether to those offering a better attentional fit, more meaning, or (ideally) both. This last option may be particularly appealing; boredom often draws people towards novel alternatives (Bench \& Lench, 2019; Kapoor et al., 2015) and sensitizes them to reward (Milyavaskaya et al., 
Figure 1

The Meaning and Attentional Components (MAC) model's predictions for how attention and meaning combine to cause discrete emotions (in bolded italics; adapted from Westgate \& Wilson, 2018)

\section{Meaning Component}

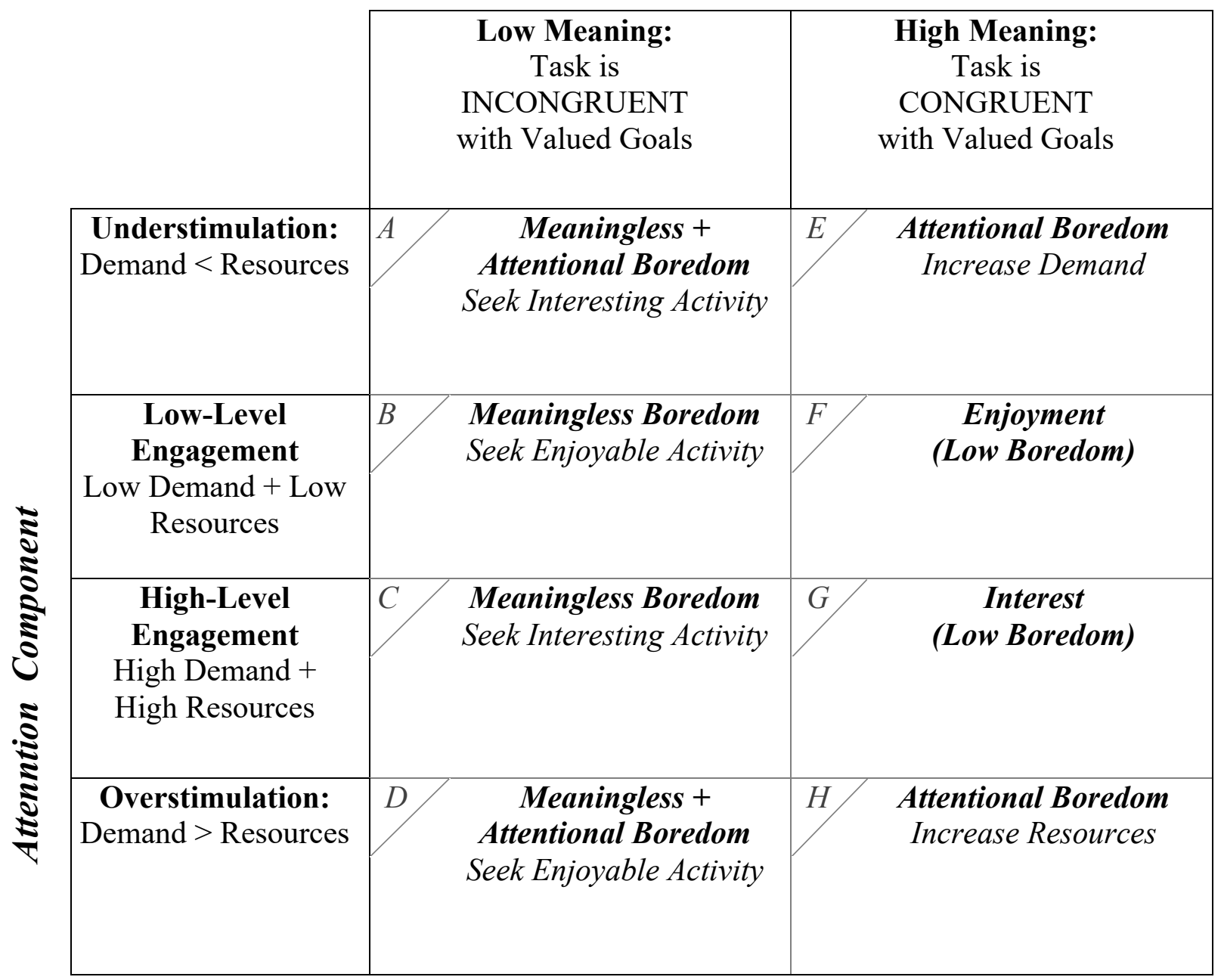

Note. Cells are lettered for ease of reference. 
2019). Indeed, experimental evidence finds that boredom leads to an impressive array of both good and "bad" behaviors, including willingness to donate to charity and behave prosocially (Pfattheicher et al., 2020; van Tilburg \& Igou, 2017), as well as willingness to harm one's self and others (Havermans et al., 2015; Nederkoorn et al., 2016; Pfattheicher et al., 2020). This variability reflects the lack of a direct link between emotions and behavior; because emotions do not directly cause behavior, downstream behaviors cannot be used to define them.

Rather emotions explain and motivate - and thus inspire action indirectly - by affectively incentivizing behavior we believe will lead us to experience more of desired emotions (e.g., happiness), and less of emotions we wish to avoid (e.g., shame; Baumeister et al., 2007).

\section{The Social Ecology of Boredom}

By defining boredom as an emotion, we can provide theoretically grounded predictions about how and why boredom (and its consequences) varies across time, space, and species. Does everyone experience boredom, and (if so) do we all experience it in the same way? Constructivist approaches to emotion would argue no (e.g., Barrett, 2009; Lindquist, 2017). Instead, meaning and attention should interact with individual and socioecological variables (including time) to create variation within and across people. Just as different environments produce different boredom outcomes, we would expect individual differences in boredom to emerge to the extent that individual, intergroup, and cultural differences affect its underlying components: attention and meaning.

\section{Regional variation in boredom}

If deficits in meaning and attention produce boredom, then boredom should not be evenly distributed across time and space: Presumably some ecological environments offer greater opportunities for meaning-making and challenge than others, and people living in such 
environments are less likely to be bored. Within the United States, some states (e.g., Ohio \& Utah) appear to experience boredom to a greater extent than others (e.g., Oregon \& Virginia), as indicated by patterns of internet search activity (Baldwin \& Westgate, 2020). Intriguingly, low boredom areas appear to have greater diversity and meaning-making potential. And these differences aren't without consequence — regional variation in boredom is linked to drug-related deaths across all 50 U.S. states, even after accounting for baseline differences in regional wellbeing. People living in boredom-prone areas might not only experience boredom more frequently due to a lack of meaning-making opportunities, but be therefore less ecologically equipped to relieve boredom.

How people experience boredom likely depends on culturally endorsed views of emotion, in general, and of boredom, in particular (Barrett, 2006a,b, 2009; Gendron et al., 2014a,b). There is considerable variation even within Westernized cultures; for instance, the German word for boredom, Langeweile, loosely translated as a "long while" or "long period of time," emphasizes its temporal component, while the French ennui conveys a sense of existential angst, stemming from the Late Latin inodaire, or "to make loathsome.” Indeed, many languages differentially emphasize boredom's attentional and existential components. Japanese, for instance, uses several terms to describe boredom; 退屈, the most common translation, has a meaning similar to that in English, but its Chinese characters originally meant to "withdraw" and "bend", implying the physical posture of being bored. 倦总, in contrast, carries a connotation of fatigue or physical exhuastion, while 飽きた, used to express the feeling of being bored, implies that one has had enough, or is satiated. Such differences are intriguing, especially in light of evidence that boredom induced by attentional deficits feels (and is experienced differently) than boredom 
induced by meaning deficits, with the latter characterized by higher arousal and greater desire for disengagement (van Hooft \& van Hooft, 2018; Westgate \& Wilson, 2018).

Do these linguistic differences reflect corresponding cultural variation in the experiential or causal components of boredom? It's possible: emotions, constructivist approaches argue, stem from the contextual categorization of sensations in the body and their perceived causes, as belonging to recognized emotion categories (Barret, 2006b). Such categories are thought to be culturally acquired, and both reflected in and learned via language (e.g., Lindquist et al., 2006, 2009, 2017); indeed, language is sometimes argued to be a prerequisite for higher-order emotion, with children exhibiting more emotional specificity and complexity with developing language acquisition (e.g., Nook et al., 2019, 2020). It follows then that some emotion constructs may be culturally specific, tailored to categorize situations of unique concern or prevalence in that society.

Using linguistics to parse emotional states has a long and well-established history in social psychology and affective science (e.g., Clore et al., 1987; Ortony et al., 1987; Oishi et al., 2013), however, it's unclear the extent to which boredom varies cross-culturally. Past research has been conducted predominantly (though not exclusively) in American, British, Canadian, and German samples. One study found that Lebanese and Hong Kongese students reported greater boredom proneness than American or Australian students, but scale items did not load equally onto factors across cultures (Sundberg et al., 1991). This is not surprising; as reviewed earlier, the trait boredom measure in question (Boredom Proneness Scale; Farmer \& Sundberg, 1986) has psychometric issues (Struk et al., 2017) which make direct comparison difficult.

More recently, researchers calibrated the Multidimensional State Boredom Scale across Chinese and Canadian samples, finding state boredom to be higher among Canadians (Ng et al., 
2015). Other studies of state boredom in Chinese and South African samples (e.g., Liu et al., 2013; Tze et al., 2013; Weybright et al., 2015; Zhou \& Long, 2012 ) have found effects generally consistent with those from "WEIRD" societies (i.e., Westernized, educated, industrialized, rich democracies; Henrich et al., 2010), but more information is needed on how, whether and why boredom differs across cultural settings. For instance, data on boredom during the Covid-19 pandemic suggests that boredom rates were much higher in some countries (e.g., Turkey, South Korea) than others (e.g., France), but it's unclear to what extent those differences reflect underlying cultural differences versus variation in public health response strategies and pathogen prevalence (Westgate, Buttrick, et al., 2020).

\section{Temporal variation in boredom}

Differences in boredom are not confined to geography. Boredom may vary not only across space, but across time; indeed, boredom is often colloquially considered to be a problem of modernity. Even the term "boredom" is quite recent, entering the English dictionary in the mid-19 ${ }^{\text {th }}$ century (1853; Oxford English Dictionary), in the midst of the industrial revolution. However, its use as is preceded by the word bore, somewhat earlier, taken to mean the act [1768] of being "tiresome or dull" (or to be a bore [1778], as in the authors responsible for boring their readers). Interestingly, people could be "in a bore" as early as the 1760s, an English expression used to describe the specifically "French" experience of having a dull time.

Were people, then, less bored in the past? It's difficult to say; evidence suggests that teenagers at least, may be becoming more bored over time (Weybright et al., 2019). In an annual survey of American teenagers, boredom remained relatively stable from 2008 to 2010, before showing a slight but statistically significant increase from 2010 through 2017 . These changes reflected an increase in self-reported boredom from approximately 3 (neutral midpoint) to 3.25 
on a 5-point scale endorsing the item "I am often bored" ( 1 = Disagree, 5 = Agree). If boredom prevalence is increasing, it may be due to technological advances that divorce individuals from traditional sources of meaning, including social relationships, meaningful work, and stable routines and communities.

\section{Situational variation in boredom: Education and the workplace}

The best available estimates suggest that stable individual differences account for only about a fifth of the variance in people's day-to-day boredom, with almost $80 \%$ due to situational factors (Chin et al., 2017). College students are bored in college classes, kids are bored at school (Pekrun et al., 2010; Pekrun et al., 2010), and adults are bored at work; boredom in highly constrained environments is common across the lifespan (Chin et al., 2017). Indeed, constraint might be one reason children and teenagers, so readily complain of boredom - they have relatively little control over their daily activities, or daily schedules. And while control is not a direct cause of boredom, it is a significant moderator (Troutwine \& O’Neal, 1981) that may make it difficult to fix underlying attention and meaning deficits.

Such constraint limits people's ability to modulate tasks at work and school in ways that are optimally challenging and meaningful, and are exacerbated by management decisions that optimize efficiency over well-being. Fisher $(1993 ; 1998)$ found that both too much and too little challenge at work was associated with boredom, and many people struggle to find work meaningful; in a recent survey, $37 \%$ of British workers thought their jobs were meaningless (Dahlgreen, 2015). David Graeber coined the term "bullshit jobs" to describe these jobs that contribute little of value to society, but are necessitated by the need to provide 9-5 employment in capitalist economies (2013). 


\section{Lifespan variation in boredom}

Conventional wisdom holds that boredom is particularly common among children and teenagers, but there is surprisingly little work on boredom in these age groups (Plummer, 2019). Boredom during free time increased modestly from the ages of 10 to 14 in a longitudinal sample of German adolescents (Spaeth et al., 2015), and about 20\% of American teenagers report high rates of boredom, a number on the rise in recent years (f et al., 2018). However, overall rates of boredom even among teenagers remain relatively low; the average American teenager in 2010 reported that they neither agreed nor disagreed with the statement "I am often bored" (Weybright et al., 2019). One of the few studies that has compared age groups directly found little difference between preschool-aged children and college students in how much they enjoy "thinking for pleasure" - both children and young adults found it equally boring (Taggart \& Lillard, 2017). Complicating the issue is that children's conceptions of emotions (including boredom) shift over time. Childhood emotions increase in complexity from simple "good-bad" evaluations to more mature adult conceptualizations, particularly as verbal knowledge develops; what boredom means to a 3-year-old may fundamentally differ from what it means to adults (Nook et al., 2018).

Cross-sectional data suggests that individual differences in boredom (e.g., "I am seldom bored") drop steadily from 18 through middle age, before largely plateauing around age 60; the limited longitudinal data available support this trend (Giambra et al., 1992). Older Americans are slightly less likely to be bored on a day-to-day basis, compared to younger ones (Chin et al., 2017), and the same is true for directed activities in the lab, such as thinking for pleasure (Wilson et al., 2019). To the extent that older adults experience less boredom, it's likely due to agerelated changes in their ability to pay attention and find meaning. Although for the most part older adults enjoy thinking about the same as younger adults, to the extent they differ, older 
adults find it slightly less boring - they're better at paying attention to their thoughts, and more motivated to enjoy them. This is consistent with evidence that older adults prioritize activities with personal meaning over extrinsic benefits and thereby experience greater meaning in life (Carstensen, 1995; Steger, et al., 2009). Older adults may also have more financial and social resources available to select activities that are meaningful and optimally challenging. The ability to self-select into certain environments and activities is an underrated distal cause of boredom; experience-sampling estimates suggest that type of activity not only accounts for up to a third of the variance in boredom during everyday life, but may partially account for boredom differences in age and income (Chin et al., 2017).

\section{Boring Thoughts, Other Minds}

Do our dogs get bored? What about elephants in the zoo? Before turning to examine boredom in non-human animals, we should pause to consider a more basic question: do nonhuman animals experience emotion at all? Non-human animals share many of the same psychological and physiological building blocks - core affect, attention, predictive coding - that combine to produce emotion in humans (Bliss-Moreau, 2017; Bliss-Moreau et al., 2018). While some have argued that language is a prerequisite for emotion (e.g., Lindquist, 2017), it is perhaps more useful to focus on the mechanism by which language is thought to facilitate emotional experience, namely via the development of emotion concepts: the grouping of particular situations into one overarching affective category (e.g., jealousy). While such concepts are clearly aided and shaped by language (largely unique to humans), they are also shaped by historical and cultural context and by lived experiences (not unique to humans) that allow for predictive coding. Thus, to the extent animals experience emotion beyond core affect, it is likely constrained by such predictive concepts. For instance, while there is some evidence that dogs 
may have a "concept" of jealousy (and behavioral reactions to it) that are similar to those in humans (Abdai et al., 2018; Harris \& Prouvost, 2014; Cook et al., 2018, cf Prato-Previde et al., 2018a,b), dogs do not appear to have a "concept" for guilt or the situations that would elicit guilt in humans (Horowitz, 2009). And, conversely, animals may experience discrete emotions for which humans lack concepts, such as the emotion of "sensing the vibrations of a dying family member's voice hundreds of miles away (as might be the case for cetaceans and elephants), or an emotion that results from the physiological consequences of a $250 \mathrm{~m}$ deep dive that has turned up a favorite food (as may be the case for California sea lions)" (Bliss-Moreau, 2017, p. 187).

There are serious ethical implications for understanding boredom in non-human animals, given the prevalence of animals in captivity (including agriculture, zoos, aquariums, and pet ownership) and questions of wildlife conservation (Burn, 2017). For instance, debate over freerange chickens has focused on how much space a chicken really wants or needs; such answers are not obvious (Dawkins et al., 2003). Debates over wildlife conservation—with serious fiscal consequences - often revolve around the protected species' needs, not only in terms of physical or nutritional requirements (e.g., sufficient prey or grazing land) but also psychological wellbeing. How much space does a wolf need to not only survive but flourish? While we know much about the former, we lack rigorous theoretical frameworks to predict the latter, often relying instead on descriptive norms, where they exist. The MAC model of boredom provides such a framework for predicting boredom in humans (Westgate \& Wilson, 2018); can it predict the needs of non-human animals as well?

There is evidence for the attentional component of boredom in animals, particularly understimulation. Fur-farmed mink housed in standard cages approach new stimuli (both pleasant and aversive) more readily than mink housed in environmentally enriched cages, as do 
mice (Meagher \& Mason, 2012). Rats likewise desire normally unwanted stimuli (e.g., flashes of bright light, non-preferred food items) after periods of monotony (Berlyne, 1960; Galef \& Whiskin, 2003). Boredom has also been used as a rationale for providing enriched environments to captive octopuses (Anderson \& Wood, 2001; Mather, 2001). Many of these findings, however, may alternatively be interpreted as failures not of attention - but of meaning.

On first glance, it may seem odd to discuss meaning in the context of non-human animals. However, meaning as defined here - the extent to which an activity is congruent with a valued and salient goal - presumes only that animals have goals (e.g., reproduction, nutrition, etc.) and are motivated to achieve them. This assumption is a critical component of operant conditioning, which is effective in both human and non-human animals. Offering a charity donation for completing an otherwise meaningless task uses the logic of operant conditioning (i.e., offering a contingent reward for performing otherwise meaningless behaviors) to reliably increase subjective meaning and reduce boredom in humans (Schmeitzky \& Freund, 2013; Westgate \& Wilson, 2018). Incentives for human study participants vary, but often take the form of food or social rewards, which are motivating for many non-human animals, as well. Thus, in theory, adding a food payoff at the end of an otherwise boring task should reduce boredom in animals, in much the same way a charity donation reduces boredom in humans - by making it more meaningful. Indeed, recent work suggests that many of the primary sources of meaning for humans (e.g., kin care) may be rooted in social motives we share in common with other nonhuman social animals (Scott \& Cohen, 2019).

While chronic boredom in captivity is clearly a concern, smaller "doses" of boredom may have similar adaptive functions in human and non-human animals. Boredom, it has been argued, may be a central motivator for play in non-human animals (Burghardt, 1984). Play behavior 
emerges when animals have sufficient resources to indulge in it; it's more common in domesticated than in wild strains of rats (Himmler et al., 2013), for instance, and less common in animals experiencing food deprivation or other adverse conditions (Baldwin \& Baldwin, 1976; Müller-Schwarze et al., 1982). Moderate stretches of boredom in the presence of good alternatives (e.g., environments to explore, objects to manipulate) may thus be an important factor in the development of play among non-human animals.

Human play in children is thought to serve similar functions, including fostering creativity in thought and behavior (Burghardt, 2015; Gasper \& Middlewood, 2014; Smith, 1982). Interestingly, boredom, under the right circumstances, is sometimes associated with increased creativity in humans (Baird et al., 2012; Gomez-Ramirez \& Kosta, 2017; Harris, 2000; Schubert, 1977, 1978; cf. Haager et al., 2018); and people who engage in creative expression, such as the arts and humanities, report greater happiness and subjective well-being (and presumably less boredom; Tay et al., 2018; see Westgate \& Oishi, 2020 for a review). Whether boredom in moderate amounts actually motivates play across species_-including nudging humans towards novels, dance, music-making, and similar forms of "play" — is an open question.

\section{Boredom in Psychological Research}

As research psychologists, we should care about boredom, if for no other reason than that many of the tasks we ask of our participants often bore them. If boredom does affect behavior, shifting people's preferences and inclinations, then it should do so as surely in our studies as it does in the lecture hall or boardroom. Implicitly we acknowledge this. Conventional wisdom for online studies is to keep them short - under five minutes, ten at maximum. The implication, of course, is that long studies increase attrition; left unspoken is why: our participants, like all people, get bored. 
We know that boredom is bad for our research. Inattention is both a cause and common symptom of boredom (Eastwood et al., 2012), and participants routinely fail attention checks, resulting in lower-quality data and attrition (Abbey \& Meloy, 2017). Indeed, interventions to boost online engagement often rely implicitly on screening out inattentive participants (e.g., Oppenheimer et al., 2009; Thomas \& Clifford, 2017), invoking intrinsic sources of meaning (e.g., reducing anonymity, emphasizing research value, explaining study purpose; Zhou \& Fishbach, 2016), and providing extrinsic incentives to make the experience more meaningful (e.g., cash payments, giftcards, but see Göritz, 2010 for potential backfire effects).

That bored participants don't pay attention is problematic, but more troubling is that boredom may alter thoughts, feelings, and behavior. For instance, boredom increases risk-taking (Steinberger et al., 2017), reward-sensitivity (Milyavskaya et al., 2017), and novelty-seeking (Bench \& Lench, 2019; Gasper \& Middlewood, 2014; Kapoor et al., 2015), all of which may actively interfere with researchers' intended targets of study. It's not uncommon in the emotion literature, for instance, for researchers to treat boredom as equivalent to an affect-free state, and thus an appropriate neutral control comparison condition in experimental inductions of emotion (Gasper, 2018). However, such an approach is not consistent with what we now know about boredom, which has been consistently found to be a negative affective state, with a wide range of distinct behavioral consequences, including those above. Early work in fMRI, for instance, assumed that participants in control conditions were in a neutral resting state (Raichle, 2015; Shulman et al., 1997). Very quickly, however, researchers realized that participants in such conditions, left to their own devices, were in fact engaging in mental activity of their own thinking, daydreaming, and mindwandering. Today, the "default mode network" is recognized as 
ongoing high activity in brain regions supporting referential mental activity, emotional processing, and memory for past experiences (Greicius et al., 2003; Raichle, 2015).

Assuming boredom to be absent in one's research protocols - or assuming its presence to be inert - can lead to inadvertent confounds. Research in the hotly debated field of ego depletion has historically used manipulations that may induce not only effortful self-control, but boredom. Circling numerals on a page, or turning pegs on a pegboard, are well-known boredom inductions; their use to this end dates back to classic work on obedience to authority (Orne, 1962) and cognitive dissonance (Festinger \& Carlsmith, 1959). Recent work suggests that boredom may partially explain declines in performance during tedious tasks (Inzlicht \& Friese, 2019; Lin et al., 2020). That is, while people may be capable of exerting self-control, they may choose not to do so if they feel bored or otherwise unmotivated (e.g., Gieseler et al., 2020; Inzlicht \& Schmeichel, 2012). If so, people should show declines in performance as boredom increases (and attention decreases) over the duration of a task, but those effects should vanish when the task ends, or when switching to a new task. Michael Inzlicht and colleagues theorize and find evidence consistent with such an account; for instance, participants exhibit small but significant depletionlike effects - namely decreases in performance and attention (but also increases in fatigue and boredom) - within a task, that then return to baseline when participants shift to a new task (Francis et al., 2020; Lin et al., 2020). Boredom and fatigue may have more in common than previously realized: notably, participants find boring tasks (e.g., passively observing number strings) even more fatiguing than cognitively effortful versions of the same task (e.g., mentally adding three to each digit of a four-digit number; Milyavaskaya et al., 2019). Other researchers have also noted this, advancing theories explicitly linking boredom to ego depletion (Wolff \& Martarelli, 2020). 
By taking boredom seriously, and seeking to eliminate it as a potential confound, we can improve our capacity to draw causal inferences. The use of online data has already necessitated steps in this direction, due to attrition in boring studies. Longitudinal designs, where item repetition may lead to boredom, use different item versions (calibrated to adjust for known differences, or equated via IRT) to limit this possibility (Salthouse et al., 2006). Cognitive psychology has also explored ways to make paradigms more interesting; for instance, Rosedahl \& Ashby (2018) tested the use of cartoon fish (in lieu of traditional Gabor patches) as stimuli. They found the cartoon fish to have a simple and well-understood perceptual presentation that could be easily varied on a number of orthogonal dimensions, and which (anecdotally) increased participant interest and reduced task fatigue. Reducing boredom in our research may not only lead to an improved experience for our participants, but better data quality, while eliminating potential confounds due to the accidental (and unwanted) intrusion of emotion into our measures and manipulations.

\section{Future Directions}

It may be surprising that an air traffic controller or a nuclear plant operator could feel bored when people's lives are at stake. Certainly none of us want to think our anesthesiologist is bored while we're lying on the operating table. But while boredom may not be pleasant, it is an effective signal. When boredom strikes, we can infer that we aren't able to pay attention or find meaning in the moment (Westgate \& Wilson, 2018). And it can occur even during critically important moments if people (including air traffic controllers and anesthesiologists) aren't thinking about their work's importance or aren't able to attend to it.

In this paper, we've provided a social psychological perspective on boredom as an emotion, examining its occurrence over the range of human (and, in some cases, non-human) 
experience. Consistently, we find evidence that boredom not only behaves like an emotion, but that treating it as one provides a useful framework for understanding its causes and consequences. Such boredom, in moderation, is adaptive - in the best case, serving as creative fuel for enriching global culture (with literature, visual art, and music) and solving our most pressing contemporary problems (e.g., artificial intelligence, wealth and resource inequality, climate change). In this light, boredom represents not just a meaningful avenue for future research, but a profoundly interesting one. 
Running Head: WHY BOREDOM MATTERS

\section{References}

Abbey, J. D., \& Meloy, M. G. (2017). Attention by design: Using attention checks to detect inattentive respondents and improve data quality. Journal of Operations Management, 53, 63-70.

Abdai, J., Terencio, C. B., Fraga, P. P., \& Miklósi, Á. (2018). Investigating jealous behaviour in dogs. Scientific Reports, 8, 1-8.

Anderson, R. C., \& Wood, J. B. (2001). Enrichment for giant pacific octopuses: Happy as a clam?. Journal of Applied Animal Welfare Science, 4, 157-168.

Aronson, E., Wilson, T. D., \& Brewer, M. B. (1998). Experimentation in social psychology. The Handbook of Social Psychology, 1, 99-142.

Baldwin, J.D., \& Baldwin, J.I. (1976). Effects of food ecology on social play: a laboratory simulation. Zeitschrift für Tierpsychologie, 40, 1-14.

Baird, B., Smallwood, J., Mrazek, M. D., Kam, J. W., Franklin, M. S., \& Schooler, J. W. (2012). Inspired by distraction: Mind wandering facilitates creative incubation. Psychological Science, 23, 1117-1122.

Baldwin, M., \& Westgate, E.C. (2020). States of boredom: Downsides to being bored in the USA. Unpublished manuscript.

Barbalet, J. M. (1999). Boredom and social meaning. The British Journal of Sociology, 50, 631646.

Barrett, L. F. (2006). Are emotions natural kinds? Perspectives on Psychological Science, 1, 2858.

Barrett, L. F. (2006). Solving the emotion paradox: Categorization and the experience of 
emotion. Personality and social psychology review, 10, 20-46.

Barrett, L. F. (2009). Variety is the spice of life: A psychological construction approach to understanding variability in emotion. Cognition and Emotion, 23, 1284-1306.

Barrett, L. F. (2017). How Emotions are Made: The secret life of the brain. Houghton Mifflin Harcourt.

Barrett, L. F., Adolphs, R., Marsella, S., Martinez, A. M., \& Pollak, S. D. (2019). Emotional expressions reconsidered: challenges to inferring emotion from human facial movements. Psychological Science in the Public Interest, 20, 1-68.

Baumeister, R. F., Vohs, K. D., Nathan DeWall, C., \& Zhang, L. (2007). How emotion shapes behavior: Feedback, anticipation, and reflection, rather than direct causation. Personality and Social Psychology Review, 11, 167-203.

Bench, S. W., \& Lench, H. C. (2019). Boredom as a seeking state: Boredom prompts the pursuit of novel (even negative) experiences. Emotion.

Berlyne, D. E. (1960). Conflict, Arousal and Curiosity. New York, NY: McGraw-Hill.

Bliss-Moreau, E. (2017). The construction of nonhuman animal emotion. Current Opinion in Psychology, 17, 184-188.

Bliss-Moreau, E., Williams, L.A., \& Karaskiewicz, C.L. (2018). The evolution of emotion in social context. In, T.K. Shackelford \& V.A. Weekes-Shackelford, The Encyclopedia of Evolutionary Psychological Science. New York, New York: Springer.

Bore. (1989). In Oxford Online Dictionary. Retrieved from https://www.oed.com/view/Entry/21637

Boredom. (1989). In Oxford Online Dictionary. Retrieved from https://www.oed.com/view/Entry/21650

Burghardt, G. M. (1984). On the origins of play. In P.K. Smith (Ed.), Play in animals and humans (pp. 5-41).

Burghardt, G. M. (2015). Creativity, play, and the pace of evolution. In Animal creativity and 
innovation (pp. 129-161). Academic Press.

Burn, C. C. (2017). Bestial boredom: a biological perspective on animal boredom and suggestions for its scientific investigation. Animal Behaviour, 130, 141-151.

Carstensen, L. L. (1995). Evidence for a life-span theory of socioemotional selectivity. Current Directions in Psychological Science, 4, 151-156.

Chater, N., Loewenstein, G.F., \& Wojtowicz, Z, Boredom and Flow: An Opportunity Cost Theory of Attention-Directing Motivational States. Doi: 10.2139/ssrn.3339123

Chin, A., Markey, A., Bhargava, S., Kassam, K. S., \& Loewenstein, G. (2017). Bored in the USA: Experience Sampling and Boredom in Everyday Life. Emotion, 17, 359-368.

Clore, G. L., Gasper, K., \& Garvin, E. (2001). Affect as information. In J. P. Forgas, (Ed.). Handbook of Affect and Social Cognition (pp. 121-144). Mahwah, NJ.: Lawrence Erlbaum Associates.

Clore, G. L., \& Ortony, A. (2013). Psychological construction in the OCC model of emotion. Emotion Review, 5, 335-343.

Clore, G. L., Ortony, A., \& Foss, M. A. (1987). The psychological foundations of the affective lexicon. Journal of Personality and Social Psychology, 53, 751.

Clore, G. L., \& Tamir, M. (2002). Affect as embodied information. Psychological Inquiry, 13, $37-45$.

Coan, J. A. (2010). Emergent ghosts of the emotion machine. Emotion Review, 2, 274-285.

Cook, P., Prichard, A., Spivak, M., \& Berns, G. S. (2018). Jealousy in dogs? Evidence from brain imaging. Animal Sentience, 3, 1 .

Csikszentmihalyi, M. (2000). Beyond boredom and anxiety: Experiencing flow in work and play. San Francisco: Jossey-Bass.

Cummings, M. L., Gao, F., \& Thornburg, K. M. (2016). Boredom in the workplace: A new look 
at an old problem. Human Factors, 58, 279-300.

Cunningham, W. A., Zelazo, P. D., Packer, D. J., \& Van Bavel, J. J. (2007). The iterative reprocessing model: A multilevel framework for attitudes and evaluation. Social Cognition, 25, 736-760.

Cunningham, W. A., Dunfield, K. A., \& Stillman, P. E. (2013). Emotional states from affective dynamics. Emotion Review, 5, 344-355.

Dahlgreen, W. (2015). 37\% of British workers think their jobs are meaningless. Lifestyle, August, 12.

Danckert, J., \& Merrifield, C. (2016). Boredom, sustained attention and the default mode network. Experimental Brain Research, 1-12.

Darrah, N. (2019). 'Bored' Wisconsin security guard handcuffs himself, forgets key at home: police. Fox News. Retrieved from: https://www.foxnews.com/us/wisconsin-bored$\underline{\text { security-guard-handcuffs }}$

Danckert, J., \& Eastwood, J. D. (2020). Out of My Skull: The Psychology of Boredom. Harvard University Press.

Dawkins, M. S., Cook, P. A., Whittingham, M. J., Mansell, K. A., \& Harper, A. E. (2003). What makes free-range broiler chickens range? In situ measurement of habitat preference. Animal Behaviour, 66, 151-160.

Eastwood, J. D., Frischen, A., Fenske, M. J., \& Smilek, D. (2012). The unengaged mind: Defining boredom in terms of attention. Perspectives on Psychological Science, 7, 482495.

Ekman, P. (1992). Are there basic emotions?. Psychological Review, 99, 550-553.

Elpidorou, A. (2018). The bored mind is a guiding mind: Toward a regulatory theory of 
boredom. Phenomenology and the Cognitive Sciences, 17, 455-484.

Elpidorou, A. (2020). Propelled: How boredom, frustration, and anticipation lead us to the good life. Oxford University Press.

Finkel, E. J., Eastwick, P. W., \& Reis, H. T. (2015). Best research practices in psychology: Illustrating epistemological and pragmatic considerations with the case of relationship science. Journal of Personality and Social Psychology, 108, 275.

Fisher, C. D. (1993). Boredom at work: A neglected concept. Human Relations, 46, 395-417.

Fisher, C. D. (1998). Effects of external and internal interruptions on boredom at work: Two studies. Journal of Organizational Behavior, 19, 503-522.

Francis, Z., Saunders, B., Umemoto, A., \& Inzlicht, M. (2020). Alleviating mental fatigue by changing tasks: A preregistered test of within-task fatigue and between-task depletion.

Galef, B. G., Jr., \& Whiskin, E. E. (2003). Preference for novel flavors in adult Norway rats (Rattus norvegicus). Journal of Comparative Psychology, 117, 96-100.

Gana, K., Broc, G., \& Bailly, N. (2019). Does the Boredom Proneness Scale capture traitness of boredom? Results from a six-year longitudinal trait-state-occasion model. Personality and Individual Differences, 139, 247-253.

Gasper, K. (2018). Utilizing Neutral Affective States in Research: Theory, Assessment, and Recommendations. Emotion Review, 10, 255-266.

Gasper, K., \& Middlewood, B. L. (2014). Approaching novel thoughts: Understanding why elation and boredom promote associative thought more than distress and relaxation. Journal of Experimental Social Psychology, 52, 50-57.

Gendron, M., Roberson, D., van der Vyver, J. M., \& Barrett, L. F. (2014). Cultural relativity in perceiving emotion from vocalizations. Psychological Science, 25, 911-920. 
Gendron, M., Roberson, D., van der Vyver, J. M., \& Barrett, L. F. (2014). Perceptions of emotion from facial expressions are not culturally universal: Evidence from a remote culture. Emotion, 14, 251.

Giambra, L. M., Camp, C. J., \& Grodsky, A. (1992). Curiosity and stimulation seeking across the adult life span: Cross-sectional and 6-to 8-year longitudinal findings. Psychology and Aging, 7, 150.

Gieseler, K., Inzlicht, M., \& Friese, M. (2020). Do people avoid mental effort after facing a highly demanding task? Journal of Experimental Social Psychology.

Goetz, T., Frenzel, A. C., Hall, N. C., Nett, U. E., Pekrun, R., \& Lipnevich, A. A. (2014). Types of boredom: An experience sampling approach. Motivation and Emotion, 38, 401-419.

Goetz, T., Frenzel, A. C., Pekrun, R., \& Hall, N. C. (2006). The domain specificity of academic emotional experiences. The Journal of Experimental Education, 75, 5-29.

Gomez-Ramirez, J., \& Costa, T. (2017). Boredom begets creativity: A solution to the exploitation-exploration trade-off in predictive coding. Biosystems, 162, 168-176.

Göritz, A. S. (2010). Using lotteries, loyalty points, and other incentives to increase participant response and completion. In S. D. Gosling \& J. A. Johnson (Eds.), Advanced methods for conducting online behavioral research (p. 219-233).

Graeber, D. (2013). On the phenomenon of bullshit jobs: A work rant. Strike Magazine, 3, 1-5.

Greicius, M. D., Krasnow, B., Reiss, A. L., \& Menon, V. (2003). Functional connectivity in the resting brain: a network analysis of the default mode hypothesis. Proceedings of the National Academy of Sciences, 100, 253-258.

Haager, J. S., Kuhbandner, C., \& Pekrun, R. (2018). To be bored or not to be bored-How taskrelated boredom influences creative performance. The Journal of Creative 
Behavior, 52, 297-304.

Hamilton, J. A. (1981). Attention, personality, and the self-regulation of mood: Absorbing interest and boredom. Progress in Experimental Personality Research, 10, 1-315.

Harris, M.B. (2000). Correlates and characteristics of boredom proneness and boredom. Journal of Applied Social Psychology, 30, 576-598.

Harris, C. R., \& Prouvost, C. (2014). Jealousy in dogs. PLoS One, 9.

Havermans, R. C., Vancleef, L., Kalamatianos, A., \& Nederkoorn, C. (2015). Eating and inflicting pain out of boredom. Appetite, 85, 52-57.

Henrich, J., Heine, S. J., \& Norenzayan, A. (2010). Most people are not WEIRD. Nature, $466,29$.

Himmler, B. T., Stryjek, R., Modlinska, K., Derksen, S. M., Pisula, W., \& Pellis, S. M. (2013). How domestication modulates play behavior: A comparative analysis between wild rats and a laboratory strain of Rattus norvegicus. Journal of Comparative Psychology, 127, 453.

Horowitz, A. (2009). Disambiguating the "guilty look": Salient prompts to a familiar dog behaviour. Behavioural Processes, 81, 447-452.

Inzlicht, M., \& Friese, M. (2019). The past, present, and future of ego depletion. Social Psychology.

Inzlicht, M., \& Schmeichel, B. J. (2012). What is ego depletion? Toward a mechanistic revision of the resource model of self-control. Perspectives on Psychological Science, 7, 450-463.

Johnson-Laird, P. N., \& Oatley, K. (1992). Basic emotions, rationality, and folk theory. Cognition \& Emotion, 6, 201-223.

Kapoor, K., Subbian, K., Srivastava, J., \& Schrater, P. (2015). Just in time recommendations: 
Modeling the dynamics of boredom in activity streams. In Proceedings of the Eighth ACM International Conference on Web Search and Data Mining (pp. 233-242). ACM.

Kass, S. J., Vodanovich, S. J., \& Callender, A. (2001). State-trait boredom: Relationship to absenteeism, tenure, and job satisfaction. Journal of Business and Psychology, 16, 317327.

Lazarus, R. S. (1991). Progress on a cognitive-motivational-relational theory of emotion. American psychologist, 46, 819-834.

Leary, M. R., Rogers, P. A., Canfeld, R. W. and Coe, C. (1986). Boredom in interpersonal encounters: Antecedents and social implications, Journal of Personality and Social Psychology, 51, 968-975.

Lin, H., Saunders, B., Friese, M., Evans, N. J., \& Inzlicht, M. (2020). Strong Effort Manipulations Reduce Response Caution: A Preregistered Reinvention of the EgoDepletion Paradigm. Psychological Science.

Lindquist, K. A. (2009). Language is powerful. Emotion Review, 1, 16-18.

Lindquist, K. A. (2017). The role of language in emotion: existing evidence and future directions. Current Opinion in Psychology, 17, 135-139.

Lindquist, K. A., Barrett, L. F., Bliss-Moreau, E., \& Russell, J. A. (2006). Language and the perception of emotion. Emotion, 6, 125.

Liu, Y., Chen, J. Z., Jiang, M., Xu, H. Y., Liu, J., Eastwood, J. D., \& Mehranvar, S. (2013). The Chinese version of the Multidimensional State Boredom Scale (MSBS): Its applicability in Chinese college students. Chinese Journal of Clinical Psychology, 21, 558-562.

Locke E. A. \& Latham G. J. (1990). A Theory of Goal Setting and Task Performance. Englewood Cliffs, NJ: Prentice 
Lowy, J., \& Henry, R. (2011). Air traffic controller suspended for watching movie on duty. The Post and Courier. Retrieved from: https://www.postandcourier.com/faa-suspendscontroller-for-watching-movie-on-duty/article 789158f9-b639-589d-ad1c$\underline{57 b 2 c a 03 b 28 a . h t m l}$

Martz, M. E., Schulenberg, J. E., Patrick, M. E., \& Kloska, D. D. (2018). “I Am So Bored!”: Prevalence Rates and Sociodemographic and Contextual Correlates of High Boredom Among American Adolescents. Youth \& Society, 50, 688-710.

Mather, J. A. (2001). Animal suffering: An invertebrate perspective. Journal of Applied Animal Welfare Science, 4, 151-156.

Meagher, R. K., \& Mason, G. J. (2012). Environmental enrichment reduces signs of boredom in caged mink. PLoS One, 7, e49180.

Milyavskaya, M., Inzlicht, M., Johnson, T., \& Larson, M. J. (2019). Reward sensitivity following boredom and cognitive effort: A high-powered neurophysiological investigation. Neuropsychologia, 123, 159-168.

Müller, G. B. (2007). Evo-devo: extending the evolutionary synthesis. Nature Reviews Genetics, 8, 943-949.

Müller-Schwarze, E., Stagge, B., \& Müller-Schwarze, C. (1982). Play behavior: persistence, decrease and energetic compensation during food shortage in deer fawns. Science, 215, 85-87.

Nederkoorn, C., Vancleef, L., Wilkenhöner, A., Claes, L., \& Havermans, R. C. (2016). Selfinflicted pain out of boredom. Psychiatry Research, 237, 127-132.

Ng, A. H., Liu, Y., Chen, J. Z., \& Eastwood, J. D. (2015). Culture and state boredom: A comparison between European Canadians and Chinese. Personality and Individual 
Differences, 75, 13-18.

Nook, E. C., Sasse, S. F., Lambert, H. K., McLaughlin, K. A., \& Somerville, L. H. (2018). The nonlinear development of emotion differentiation: Granular emotional experience is low in adolescence. Psychological Science, 29, 1346-1357.

Nook, E. C., Stavish, C. M., Sasse, S. F., Lambert, H. K., Mair, P., McLaughlin, K. A., \& Somerville, L. H. (2020). Charting the development of emotion comprehension and abstraction from childhood to adulthood using observer-rated and linguistic measures. Emotion.

Novak, R. (2012). Is anesthesia 99\% boredom and 1\% panic? Retrieved from: https://theanesthesiaconsultant.com/2012/07/15/is-anesthesia-99-boredom-and-1-panic-2/

Oishi, S., Graham, J., Kesebir, S., \& Galinha, I. C. (2013). Concepts of happiness across time and cultures. Personality and Social Psychology Bulletin, 39), 559-577.

Oppenheimer D. M., Meyvis T., Davidenko N. (2009). Instructional manipulation checks: detecting satisficing to increase statistical power. Journal of Experimental Social Psychology, 45. 867-872.

Orne, M. T. (1962). On the social psychology of the psychological experiment: With particular reference to demand characteristics and their implications. American Psychologist, 17.

Ortony, A., Clore, G. L., \& Collins A. (1988). The Cognitive Structure of Emotions. New York: Cambridge University Press.

Ortony, A., Clore, G. L., \& Foss, M. A. (1987). The referential structure of the affective lexicon. Cognitive Science, 11, 341-364.

Ortony, A., \& Turner, T. J. (1990). What's basie about basic emotions? Psychological Review, 97, 315-331. 
Pekrun, R. (2006). The control-value theory of achievement emotions: Assumptions, corollaries, and implications for educational research and practice. Educational Psychology Review, 18, 315-341.

Pekrun, R., Goetz, T., Daniels, L. M., Stupnisky, R. H., \& Perry, R. P. (2010). Boredom in achievement settings: Exploring control-value antecedents and performance outcomes of a neglected emotion. Journal of Educational Psychology, 102, 531-549.

Pfattheicher, S, Lazarević, L.B., Westgate E.C., \& Schindler, S. (2020). On the relation of boredom and sadism. Unpublished manuscript.

Plummer, B. A. (2019). Boring Into the State of Boredom Through Age Groups: Types of Boredom and Strategies to Increase Motivation and Positive Life Outcomes. In Ethical Problem-Solving and Decision-Making for Positive and Conclusive Outcomes (pp. 5777).

Posner, J., Russell, J. A., \& Peterson, B. S. (2005). The circumplex model of affect: An integrative approach to affective neuroscience, cognitive development, and psychopathology. Development and Psychopathology, 17, 715-734.

Prato-Previde, E., Nicotra, V., Poli, S. F., Pelosi, A., \& Valsecchi, P. (2018). Do dogs exhibit jealous behaviors when their owner attends to their companion dog?. Animal Cognition, 21, 703-713.

Prato-Previde, E., Nicotra, V., Pelosi, A., \& Valsecchi, P. (2018). Pet dogs' behavior when the owner and an unfamiliar person attend to a faux rival. PloS one, 13.

Raichle, M. E. (2015). The brain's default mode network. Annual Review of Neuroscience, 38, 433-447.

Rosedahl, L., \& Ashby, F. G. (2018). A New Stimulus Set for Cognitive Research. Dimension, $20,60-80$. 
Salthouse, T. A., Nesselroade, J. R., \& Berish, D. E. (2006). Short-term variability in cognitive performance and the calibration of longitudinal change. The Journals of Gerontology Series B: Psychological Sciences and Social Sciences, 61, P144-P151.

Schachter, S., \& Singer, J. (1962). Cognitive, social, and physiological determinants of emotional state. Psychological Review, 69, 379.

Schmeitzky, J.R., \& Freund, A.M. (2013). Goal Focus and the Experience of Boredom. Poster presented at the Max Planck Institute on the LIFE Course, Ann Arbor, Michigan.

Schubert, D.S. (1977). Boredom as an antagonist of creativity. Journal of Creative Behaviors, $11,233-240$.

Schubert, D.S. (1978). Creativity and coping with boredom. Psychiatric Annals, 8, 46-54.

Scott, M. J., \& Cohen, A. B. (2019). Surviving and thriving: Fundamental social motives provide purpose in life. Personality and Social Psychology Bulletin.

Shulman G.L., Fiez, J.A., Corbetta, M., Buckner, R.L., Miezin, F.M., et al. 1997. Common blood flow changes across visual tasks: II. Decreases in cerebral cortex. Journal of Cognitive Neuroscience, 9, 648-663.

Siegel, E. H., Sands, M. K., Van den Noortgate, W., Condon, P., Chang, Y., Dy, J., ... \& Barrett, L. F. (2018). Emotion fingerprints or emotion populations? A meta-analytic investigation of autonomic features of emotion categories. Psychological Bulletin, 144, 343.

Silvia, P. J. (2005). What is interesting? Exploring the appraisal structure of interest. Emotion, 5,89 .

Silvia, P. J. (2006). Exploring the Psychology of Interest. Oxford University Press.

Silvia, P. J. (2008). Interest—The curious emotion. Current Directions in Psychological Science, 17, 57-60.

Smith, P. K. (1982). Does play matter? Functional and evolutionary aspects of animal and human 
play. Behavioral and brain sciences, 5, 139-155.

Smith, C. A., \& Ellsworth, P. C. (1985). Patterns of Cognitive Appraisal in Emotion. Journal of Personality and Social Psychology, 48, 813-838.

Spaeth, M., Weichold, K., \& Silbereisen, R. K. (2015). The development of leisure boredom in early adolescence: Predictors and longitudinal associations with delinquency and depression. Developmental psychology, 51, 1380.

Steger, M. F., Oishi, S., \& Kashdan, T. B. (2009). Meaning in life across the life span: Levels and correlates of meaning in life from emerging adulthood to older adulthood. The Journal of Positive Psychology, 4, 43-52.

Steinberger, F., Schroeter, R., \& Watling, C. N. (2017). From road distraction to safe driving: Evaluating the effects of boredom and gamification on driving behavior, physiological arousal, and subjective experience. Computers in Human Behavior, 75, 714-726.

Struk, A. A., Carriere, J. S., Cheyne, J. A., \& Danckert, J. (2017). A short Boredom Proneness Scale: development and psychometric properties. Assessment, 24, 346-359.

Sundberg, N. D., Latkin, C. A., Farmer, R. F., \& Saoud, J. (1991). Boredom in Young Adults: Gender and Cultural Comparisons. Journal of Cross-Cultural Psychology, 22, 209-223.

Taggart, J., \& Lillard, A. (April 2017). When There's a Will and a Way: Does Children's Enjoyment of "Just Thinking” Depend on Contextual Framing and Executive Function? Poster presented at the biennial meeting of the Society for Research in Child Development, Austin, TX.

Tay, L., Pawelski, J. O., \& Keith, M. G. (2018). The role of the arts and humanities in human flourishing: A conceptual model. The Journal of Positive Psychology, 13(3), 215-225.

Thomas K. A., Clifford S. (2017). Validity and mechanical Turk: an assessment of exclusion methods and interactive experiments. Computers in Human Behavior, 77, 184-197.

Troutwine, R., \& O’Neal, E. C. (1981). Volition, performance of a boring task and time 
estimation. Perceptual and Motor Skills, 52, 865-866.

Tze, V. M., Daniels, L. M., Klassen, R. M., \& Li, J. C. H. (2013). Canadian and Chinese university students' approaches to coping with academic boredom. Learning and Individual Differences, 23, 32-43.

van Hooft, E.A.J. \& van Hooff, M.L.M. (2018). The state of boredom: Frustrating or depressing? Motivation and Emotion, 42, 931-946.

van Tilburg, W. A., \& Igou, E. R. (2012). On boredom: Lack of challenge and meaning as distinct boredom experiences. Motivation and Emotion, 36, 181-194.

van Tilburg, W. A., \& Igou, E. R. (2016). Boredom begs to differ: Differentiation from other negative emotions. Emotion. In press.

van Tilburg, W. A., \& Igou, E. R. (2017). Can boredom help? Increased prosocial intentions in response to boredom. Self and Identity, 1-15.

Yamamoto, N., \& Ishikawa, M. (2010). Curiosity and boredom based on prediction error as novel internal rewards. In Brain-Inspired Information Technology (pp. 51-55). Springer , Berlin, Heidelberg.

Westgate, E.C. (2020). Why boredom is interesting. Current Directions in Psychological Science.

Westgate, E.C., Buttrick, N.B., Lin, Y., ..., \& Leander, P. (2020). Boredom and Public Health: Predicting boredom and its consequences during self-isolation and quarantine in Covid-19. Unpublished data.

Westgate, E.C., \& Fairbairn, C.A. (2020). Buzzed, but not bored: How boredom leads to "bad" behavior. Unpublished manuscript.

Westgate, E.C. \& Oishi, S. (2020). Art, music, and literature: Do the humanities make our lives 
richer, happier, and more meaningful? In J. Pawelski \& L. Tay (Ed.), Handbook of Positive Psychology on the Arts and Humanities: Theory and Research. Oxford University Press.

Westgate, E. C., \& Wilson, T. D. (2018). Boring thoughts and bored minds: The MAC model of boredom and cognitive engagement. Psychological Review, 125, 689-713.

Westgate, E. C., Wilson, T. D., \& Gilbert, D. T. (2017). With a little help for our thoughts: Making it easier to think for pleasure. Emotion, 17, 828-839.

Weybright, E. H., Caldwell, L. L., Ram, N., Smith, E. A., \& Wegner, L. (2015). Boredom prone or nothing to do? Distinguishing between state and trait leisure boredom and its association with substance use in South African adolescents. Leisure Sciences, 37, 311331.

Weybright, E. H., Schulenberg, J., \& Caldwell, L. L. (2019). More bored today than yesterday? National trends in adolescent boredom from 2008 to 2017. Journal of Adolescent Health. Wilson, T. D., Aronson, E., \& Carlsmith, K. (2010). The art of laboratory experimentation. In S. T. Fiske, D. T. Gilbert, \& G. Lindzey (Eds.), Handbook of social psychology (p. 51-81). John Wiley \& Sons Inc.

Wilson, T. D., Reinhard, D. A., Westgate, E. C., Gilbert, D. T., Ellerbeck, N., Hahn, C., Brown, C.L., . \& Shaked, A. (2014). Just think: the challenges of the disengaged mind. Science, 345, 75-77.

Wilson, T. D., Westgate, E. C., Buttrick, N. R., \& Gilbert, D. T. (2019). The mind is its own place: The difficulties and benefits of thinking for pleasure. In J.M. Oleson (Ed.), Advances in Experimental Social Psychology.

Wolff, W., \& Martarelli, C. (2020). Bored into depletion? Towards a tentative integration of 
perceived self-control exertion and boredom as guiding signals for goal-directed behavior. Perspectives on Psychological Science.

Zhou, H., \& Fishbach, A. (2016). The pitfall of experimenting on the web: How unattended selective attrition leads to surprising (yet false) research conclusions. Journal of Personality and Social Psychology, 111, 493.

Zhou, S. X., \& Leung, L. (2012). Gratification, loneliness, leisure boredom, and self-esteem as predictors of SNS-game addiction and usage pattern among Chinese college students. International Journal of Cyber Behavior, Psychology and Learning (IJCBPL), 2, 34-48. 
